\title{
Implication of Endothelin-2 and Oxidative Stress Biomarkers in Essential Hypertension
}

\author{
Veena Dhawan ${ }^{1 *}$, Indu Sharma ${ }^{1}$, Nitin Mahajan ${ }^{1,3}$, Sonal Malik Sangwan ${ }^{1}$, and Sanjay Jain ${ }^{2}$ \\ ${ }^{1}$ Department of Experimental Medicine \& Biotechnology, Postgraduate Institute of Medical Education \& Research (PGIMER), Chandigarh-160012, India \\ ${ }^{2}$ Department of Internal Medicine, Postgraduate Institute of Medical Education and Research (PGIMER), Chandigarh-160012, India \\ ${ }^{3}$ Department of Internal Medicine, Division of Molecular Oncology, Washington University, St. Louis, Missouri-63108, USA
}

\begin{abstract}
Objectives: Essential hypertension $(\mathrm{EH})$ is a multifactorial disease and oxidative stress has been demonstrated to play an important role in its pathophysiology. Among several genes implicated in the pathophysiology of hypertension, endothelin-2 (ET-2), a potent vasoconstrictor, has been incriminated as a candidate gene for essential hypertension. To find out correlation of in vivo biomarkers of oxidative stress [oxidized low density lipoprotein (Ox-LDL), 8-isoProstaglandin $\mathrm{F}_{2 \alpha}\left(8\right.$-iso- $\left.\mathrm{PGF}_{2 \alpha}\right)$ ] and Nitrite $\left(\mathrm{NO}_{2}\right)$ are related to endothelin-2 levels and to determine their value as diagnostic markers in essential hypertension.

Methods: 100 subjects with essential hypertension and 150 age and sex-matched normotensive controls were enrolled to determine levels of ET-2, Ox-LDL, 8-iso-PGF ${ }_{2 \alpha}$ and $\mathrm{NO}_{2-}$

Results: We observed significantly augmented levels of ET-2 ( $P<0.001)$, Ox-LDL $(P<0.001), 8$-iso- $P G F_{2 \alpha}(P<0.001)$ and nitrite $(P<0.001)$ in EH subjects as compared to the normal healthy controls. ET-2 demonstrated a positive and significant correlation with Ox-LDL, 8-iso-PGF ${ }_{2 a}$, and nitrite levels in subjects with $\mathrm{EH}$. ROC curve analysis revealed that all these variables were significantly able to distinguish $\mathrm{EH}$ subjects and controls with high sensitivity and specificity.
\end{abstract}

Conclusions: TOur findings highlight implication of these variables as potential markers for the disease and as possible targets for therapeutic management of the essential hypertension.

Keywords: Essentialhypertension; Oxidative stress; Vasoconstriction; Endothelin-2; Ox-LDL; 8-isoPGF ${ }_{2 \alpha}$

\section{Introduction}

Hypertension is one of the major risk factors that contribute to cardiovascular and cerebrovascular endpoints. Currently, it is reported that $16.5 \%$ of all the deaths worldwide are due to hypertension of which $51 \%$ are due to stroke and $45 \%$ due to coronary heart disease (CHD) respectively [1-4]. The molecular basis of Essential Hypertension (EH) is multifactorial, complex and poorly understood and recent interest is directed towards investigating the possible role of vascular hemostasis. The endothelium is recognized as an extremely active source of vasoactive substances e.g. vasodilators and vasoconstrictors; the balance of which maintains vascular tone $[5,6]$. Endothelin-2 is a member of the endothelin protein family (ET-1, ET-2 and ET-3) of secretory vasoconstrictive peptides that bind to G-protein-coupled receptors (GPCR), ET-RA and ET-RB. ET-1 is known as one of the most powerful vasoconstrictors in the vasculature [7-9]. Although, ET-2 is very similar in structure as well as pharmacology to ET-1, studies in knockout mice and in cardiovascular system suggest that ET-2 may have a pathophysiologically distinct role than ET-1, that may be accomplished at the level of gene expression or in their synthesis and therefore, may act as different drug targets. Besides, mediating vasoconstriction, endothelins are shown to regulate growth in several cell types and may also affect differentiation, inflammation and angiogenesis [7].

Endothelial dysfunction may occur as a consequence of increased endothelin production and studies have shown that endothelial dysfunction and oxidative stress are associated with essential hypertension. Endothelial dysfunction may result in the generation of reactive oxygen species causing oxidative stress. Oxidized low density lipoprotein (Ox-LDL) is an independent predictor of endothelial dysfunction, with pro-inflammatory, prothrombotic and pro-apoptotic properties in individuals suffering from oxidative stress, such as in diabetics [10-12]. During hypertension, heightened oxidative stress milieu may result in increased generation of ox-LDL, increased lipid peroxidation and NO depletion which seem to be vital for the onset and chronicity of hypertension and vascular disorders. ROS may be produced by the NADPH oxidases, uncoupled nitric oxide synthase, xanthine oxidase and by mitochondrial sources that not only contribute to hypertension, but also cause vascular disease and endothelial dysfunction [13].

8-isoprostagandin $\mathrm{F}_{2 \alpha}\left(8\right.$-isoPGF $\left.\mathrm{P}_{2 \alpha}\right)$ belongs to the complex family of isoprostanes and is shown to be a sensitive and specific biomarker of oxidative stress in vivo. Products of the isoprostane pathway are shown to exert potent biological actions and therefore, may participate as physiological mediators of the disease [14]. F2-isoprostanes are PG isomers generated nonenzymatically through free radical-catalyzed attack of esterified arachidonic acid in cell membranes and lipoproteins and have emerged as one of the most important tools to explore the role of oxidative stress in the pathogenesis of a wide range of human diseases [15-17]. Best et al demonstrated that ET-antagonists significantly ameliorated oxidative stress in $\mathrm{HCH}$ pigs via restoring $\mathrm{NO}$ bioavailability and by restoring isoprostanes [18]. Increased oxidative

*Corresponding author: Veena Dhawan, Additional Professor, Department of Experimental Medicine \& Biotechnology, Research Block 'B', Postgraduate Institute of Medical Education \& Research (PGIMER), Chandigarh-160012, India, Tel: 91-172-2747585; Fax: 91-172-2744401; E-mail: veenad2001@yahoo.com

Received May 20, 2014; Accepted Aug 28, 2014; Published September 02, 2014 Citation: Dhawan V, Sharma I, Mahajan N, Sangwan SM, Jain S (2014) Implication of Endothelin-2 and Oxidative Stress Biomarkers in Essential Hypertension. J Hypertens 3: 170. doi:10.4172/2167-1095.1000170

Copyright: (c) 2014 Tyson CC, et al. This is an open-access article distributed under the terms of the Creative Commons Attribution License, which permits unrestricted use, distribution, and reproduction in any medium, provided the original author and source are credited. 
stress is shown to result in decreased nitric oxide (NO) availability which is essentially required for maintaining vascular tone and stability, resulting in endothelial dysfunction indirectly. These observations indicate that there is a need to evaluate whether endothelin stimulates oxidative stress or oxidative stress stimulates endothelin production.

Several studies have reported the mechanism of action of ET-1 in the regulation of blood pressure and its pathogenesis. However, so far the relationship between ET-2, oxidative stress and associated hypertension is far from clear and nothing is virtually known about the role ET-2 plays in essential hypertension. Therefore, the present study aims to determine the status of ET-2 in essential hypertensive subjects and to find its relationship with oxidative stress biomarkers i.e. ox-LDL, 8 -isoPGF ${ }_{2 \alpha}$ and nitrite.

\section{Methods}

\section{Experimental design}

The present study was approved by the Institute Ethics Committee of Postgraduate Institute of Medical Education and Research (PGIMER), Chandigarh. A fully informed written consent was obtained from all these subjects prior to their participation in the study. The subjects were enrolled from the outdoor Hypertension Clinic of the Postgraduate Institute of Medical Education and Research (PGIMER), Chandigarh. Each participant enrolled for the study underwent a detailed clinical examination.

The blood pressure measurements were carried out as per JNC VI recommendation [19]. Hypertension was defined clinically as blood pressure of $\geq 140 / 90$ measured on three different occasions. Blood pressure was measured twice after the subjects had been resting in the supine position for 10 minutes with the use of an appropriate cuff size in relation to arm size. Diastolic blood pressure (DBP) was determined as Korotokoff phase V. A 12-lead standard electrocardiogram (ECG) was also recorded. A total of 250 North Indian study subjects were enrolled in the present study. 100 subjects with clinically defined essential hypertension (EH) and 150 healthy, normotensive volunteers (Controls) belonging to the same ethnic origin and socio-economic background were enrolled in the present study.

Any participant with a previous history of coronary artery disease, secondary hypertension, diabetes mellitus, febrile conditions, known malignant disease, known cardiomyopathy, acute or chronic inflammatory disease, vascular diseases related to the connective tissue disorders and subjects with creatinine levels $>1.3 \mathrm{mg}$ were excluded from the study. The $\mathrm{EH}$ patients were on standard anti-hypertensives such as Ramipril ( $5 \mathrm{mg} / \mathrm{d})$, Atenolol $(50 \mathrm{mg} / \mathrm{d})$, Amlodipine $(5 \mathrm{mg} / \mathrm{d})$ and Hydrochlorothiazide $(25 \mathrm{mg} / \mathrm{d})$. It was ensured that the control subjects were not taking any anti-inflammatory drugs, anti-oxidant supplements or any alternative medicine. The data for ethnic origin, age, sex, cigarette smoking, body mass index (BMI) $\left(\mathrm{Kg} / \mathrm{m}^{2}\right)$ and alcohol consumption was recorded for each subject participating in the study.

Venous blood was collected in the morning from the overnight fasting subjects from anticubital vein into plain sterile tube for serum and in EDTA for plasma. Serum/ plasma was separated and stored at $-80^{\circ} \mathrm{C}$ for further analysis.

Each participant underwent baseline biochemical investigations which included a complete hemogram, fasting blood glucose, blood urea, serum creatinine and routine urine analysis. Serum Total Cholesterol (TC), Triglycerides (TG) and High-Density Lipoprotein Cholesterol Levels (HDL-C) levels were measured with standard enzymatic kits
(Accurex Biomedical Pvt. Ltd.). Low-Density Lipoprotein Cholesterol (LDL-C) and Very Low-Density Lipoprotein (VLDL-C) values were calculated using Friedwald's formula [20].

\section{Determination of Endothelin-2 (ET-2)}

The plasma levels of endothelin-2 were determined using a commercially available EIA kit (Cat \# EK-023-13; Phoenix Pharmaceuticals, Inc., California, USA). The intra and inter-assay coefficient of variation for the assay were $<5$ and $<14 \%$ respectively. The minimum detection limit of the assay was $0.25 \mathrm{ng} / \mathrm{ml}$. Data was expressed as $\mathrm{ng} / \mathrm{ml}$

\section{Determination of Oxidized low density lipoprotein (Ox-LDL)}

Levels of plasma Ox-LDL were measured using a commercially available sandwich ELISA kit (Cat \# 10-1143-01, Mercodia, Uppsala, Sweden). The intra- and inter-assay coefficient of variation for the assay was 4.5 and $7 \%$ respectively. The detection limit of the assay was $<1 \mathrm{mU} / \mathrm{l}$. Data was expressed as U/l.

\section{Determination of Plasma 8-isoprostaglandin $F_{2 a}\left(8\right.$-isoPGF $\left.{ }_{2 a}\right)$}

Plasma 8 -isoPGF $2 a$ was determined as a sensitive and specific biomarker of in vivo oxidative stress in all the patients with $\mathrm{EH}$ and control subjects by using commercially available enzyme immunoassay kit (Cat \# 900-010; Assay Designs, Inc., Michigan, USA) according to the manufacturer's instructions. The detection limit of quantification was $5 \mathrm{pg} / \mathrm{ml}$. The intra and inter-assay coefficient of variation were 5.0 and $5.5 \%$ respectively and the results for 8 -isoPGF ${ }_{2 \alpha}$ was expressed in $\mathrm{ng} / \mathrm{ml}$.

\section{Determination of plasma nitrite}

Plasma nitrite $\left(\mathrm{NO}_{2}\right)$, as a stable end product of nitric oxide (NO) metabolism was measured by the method of Green et al [21] employing modification of Greiss reaction, as described previously [22].

\section{Statistical analysis}

Statistical analysis was performed using SPSS 17.0 for Windows (SPSS Inc, Chicago, IL, USA). Data was presented as mean \pm SD. The Kolmogorov-Smirnov test of normality was used to verify whether the distribution of variables followed a Gaussian pattern and were analyzed by comparing their means by unpaired Student's t-test. Variables not showing Gaussian distribution were analyzed by non-parametric Mann Whitney $\mathrm{U}$ test. Correlations between the variables were analyzed with Pearson's coefficient. Multivariate logistic regression analysis was performed to determine the association between essential hypertension (EH) and all other variables. Receiver operating characteristic (ROC) curves were constructed to determine the optimal values of variables, which provided high sensitivity and specificity.

\section{Results}

The anthropometric characteristics of the subjects are depicted in Table 1. The two study groups were comparable with respect to smoking, alcohol, BMI, weight and height. However, there was significant difference between the two groups in age (Table 1). Mean systolic blood pressure (SBP) recordings as well as diastolic blood pressure (DBP) recordings were found to be significantly higher in $\mathrm{EH}$ group as compared to the control group $(\mathrm{P}<0.001)$. As far as lipids and lipoprotein levels are concerned, significantly higher levels of serum TG $(\mathrm{P}<0.05)$ and HDL-C $(\mathrm{P}<0.01)$ were observed in $\mathrm{EH}$ subjects. As far as, serum TC, LDL-C and VLDL-C levels are concerned no significant difference was observed between the two study groups. The circulating 
Citation: Dhawan V, Sharma I, Mahajan N, Sangwan SM, Jain S (2014) Implication of Endothelin-2 and Oxidative Stress Biomarkers in Essential Hypertension. J Hypertens 3: 170. doi:10.4172/2167-1095.1000170

Page 3 of 7

levels of ET-2 $(\mathrm{P}<0.001)$, Ox-LDL $(\mathrm{P}<0.001), 8$-isoPGF $\mathrm{P}_{2 \alpha}(\mathrm{P}<0.001)$ and plasma nitrite $(\mathrm{P}<0.001)$ were found to be significantly higher in patients with $\mathrm{EH}$ as compared to their control counterparts (Table 1 and Figure 1).

Correlation analysis was performed to analyze the relationship among different laboratory measures from cohorts of $\mathrm{EH}$ patients (Table 2 ). Both SBP and DBP were found to be positively and significantly correlated with ET-2, Ox-LDL, 8-isoPGF ${ }_{2 a}$ and nitrite levels. Further, a significant and positive correlation was also observed among the major study variables i.e. ET-2, Ox-LDL, 8-isoPGF ${ }_{2 a}$ and plasma nitrite levels (Table 2).

Multivariate logistic regression analysis was performed to determine the association of the variables with hypertension (Table
3). Our data demonstrated that except BMI, age, TG, HDL-C, ET2, Ox-LDL, 8-iso-PGF ${ }_{2 \alpha}$ and nitrite levels demonstrated significant association with essential hypertension as evident by significant odds ratio (Table 3). As plasma ET-2, Ox-LDL, 8-iso-PGF 2 and nitrite levels achieved significance both by correlation analysis and multivariate logistic regression analysis, ROC curves were constructed to determine the optimal values, which provide high sensitivity and specificity (Table 4 and Figure 2). The area under the curve (AUC) was determined, which was significant for all the four variables under consideration. The sensitivity and specificity were calculated for each possible threshold value of estimated probability for the respective group. Cut-off value for ET-2 levels, which achieved an optimal sensitivity of $69.5 \%$ and specificity of $71.1 \%$ was $3.18 \mathrm{ng} / \mathrm{ml}$, for Ox-LDL levels, $92.6 \%$ sensitivity and $56.3 \%$ specificity was achieved at $61.5 \mathrm{U} / \mathrm{ml}$, for 8 -isoPGF $F_{2 a}$ levels

\begin{tabular}{|c|c|c|c|}
\hline Variables & $\mathrm{EH}(n=100)$ & Controls $(n=150)$ & $\mathbf{P}$ \\
\hline Age (Years) & $46.1 \pm 13.4$ & $39.9 \pm 10.5$ & $0.000^{\star * *}$ \\
\hline Sex (M:F) & 101:96 & $78: 63$ & - \\
\hline Smokers & 9 & 7 & - \\
\hline Alcohol Intake & 18 & 8 & - \\
\hline BMI $\left(\mathrm{Kg} / \mathrm{m}^{2}\right)$ & $25.8 \pm 3.8$ & $24.7 \pm 3.6$ & $0.025^{*}$ \\
\hline $\mathrm{SBP}(\mathrm{mmHg})$ & $145.07 \pm 11.6$ & $119.33 \pm 6.9$ & $0.000^{\star \star *}(U)$ \\
\hline $\mathrm{DBP}(\mathrm{mmHg})$ & $94.06 \pm 6.18$ & $78.99 \pm 4.4$ & $0.000^{* * *}(U)$ \\
\hline TC (mg/dl) & $190.17 \pm 39.8$ & $186.83 \pm 36.7$ & 0.512 \\
\hline TG (mg/dl) & $162.13 \pm 78.07$ & $136.05 \pm 56.09$ & $0.027^{\star}(U)$ \\
\hline LDL-C (mg/dl) & $112.47 \pm 39.03$ & $116.17 \pm 37.09$ & 0.466 \\
\hline VLDL-C (mg/dl) & $32.38 \pm 15.59$ & $30.05 \pm 16.73$ & $0.153(U)$ \\
\hline HDL-C (mg/dl) & $45.32 \pm 12.6$ & $40.70 \pm 8.3$ & $0.001^{* *}$ \\
\hline ET-2 (ng/ml) & $6.75 \pm 4.9$ & $3.23 \pm 2.1$ & $0.000^{* * *}(U)$ \\
\hline Ox-LDL (ng/ml) & $117.43 \pm 50.73$ & $66.26 \pm 42.7$ & $0.000^{* \star *}(U)$ \\
\hline 8-IsoPGF ${ }_{2 \alpha}(\mathrm{ng} / \mathrm{ml})$ & $213.0 \pm 149.21$ & $91.75 \pm 38.33$ & $0.000^{* \star *}(U)$ \\
\hline Nitrite $\left(\mathrm{No}_{2}^{-}\right)(\mu \mathrm{M})$ & $1023.5 \pm 355.99$ & $735.58 \pm 244.8$ & $0.000^{\star \star \star}$ \\
\hline
\end{tabular}

Note: Data is expressed as mean $\pm \mathrm{SD} ; \mathrm{n}=$ number of study subjects; ${ }^{*} \mathrm{P}<0.05 ;{ }^{* *} \mathrm{P}<0.01$; ${ }^{* * *} \mathrm{P}<0.001$; $\mathrm{U}=$ Variables analyzed by Mann Whitney $U$ test.

Table 1: Anthropometric statistics of the study subjects
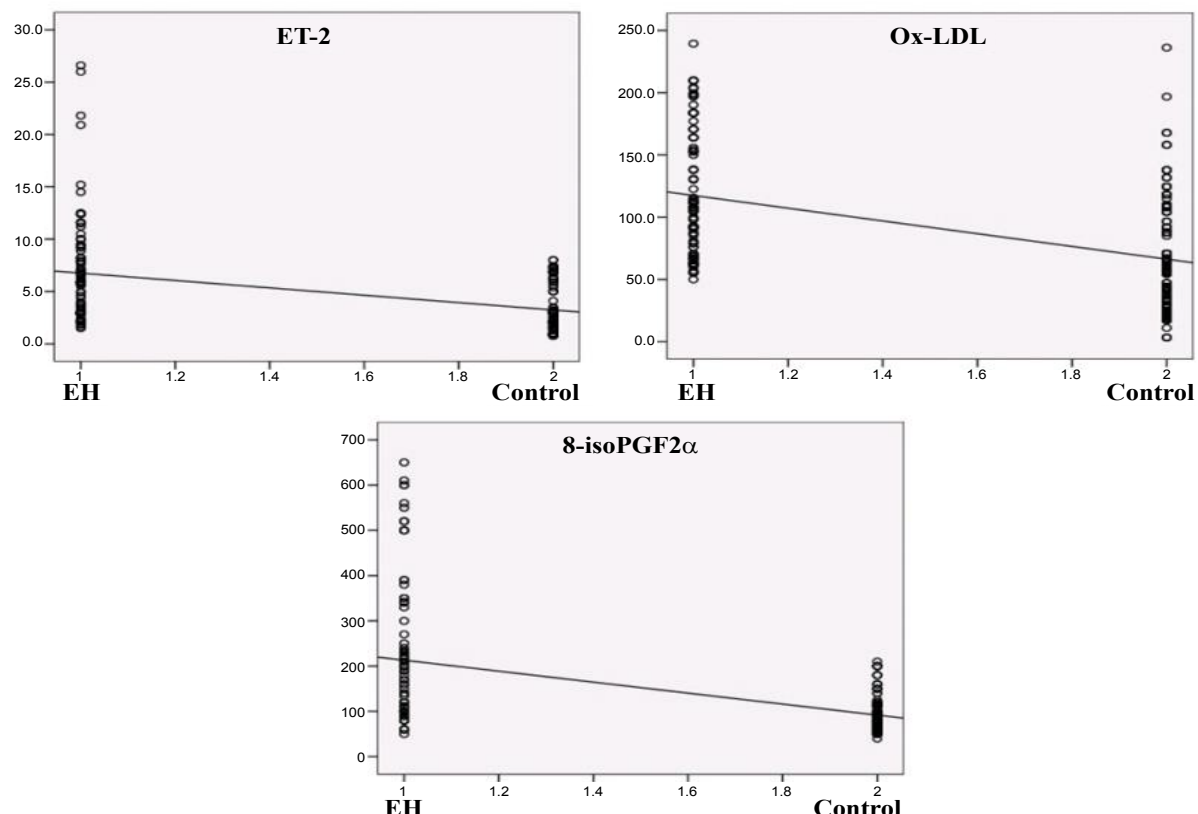

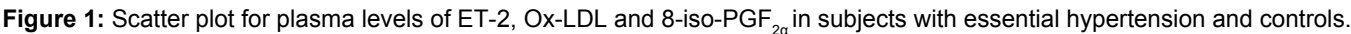


Citation: Dhawan V, Sharma I, Mahajan N, Sangwan SM, Jain S (2014) Implication of Endothelin-2 and Oxidative Stress Biomarkers in Essential Hypertension. J Hypertens 3: 170. doi:10.4172/2167-1095.1000170

Page 4 of 7

\begin{tabular}{|c|c|c|c|c|c|c|c|c|}
\hline Variables & SBP & DBP & TG & HDL-C & ET-2 & Ox-LDL & 8-IsoPGF ${ }_{2 \alpha}$ & Nitrite \\
\hline SBP & 1 & $0.804^{* *}$ & $0.174^{\star *}$ & 0.123 & $0.351^{* *}$ & $0.390^{* *}$ & $0.428^{* *}$ & $0.421^{* *}$ \\
\hline DBP & $0.804^{* *}$ & 1 & 0.102 & 0.087 & $0.335^{\star *}$ & $0.384^{* *}$ & $0.390^{* *}$ & $0.466^{\star *}$ \\
\hline TG & $0.174^{* *}$ & 0.102 & 1 & -0.096 & 0.088 & 0.020 & 0.098 & 0.083 \\
\hline HDL-C & 0.123 & 0.087 & -0.096 & 1 & $0.161^{*}$ & $0.155^{*}$ & 0.101 & 0.029 \\
\hline ET-2 & $0.351^{* *}$ & $0.335^{\star *}$ & 0.088 & $0.161^{*}$ & 1 & $0.458^{* *}$ & $0.224^{* *}$ & $0.203^{* *}$ \\
\hline Ox-LDL & $0.390^{* *}$ & $0.384^{* *}$ & 0.020 & $0.155^{*}$ & $0.458^{* *}$ & 1 & $0.321^{* *}$ & $0.278^{* *}$ \\
\hline 8-isoPGF $2 a$ & $0.428^{* *}$ & $0.390^{* *}$ & 0.098 & 0.101 & $0.224^{* *}$ & $0.321^{* *}$ & 1 & $0.168^{*}$ \\
\hline Nitrite & $0.421^{* *}$ & $0.466^{\star \star}$ & 0.083 & 0.029 & $0.203^{\star *}$ & $0.278^{\star *}$ & $0.168^{*}$ & 1 \\
\hline
\end{tabular}

Table 2: Associations between variables as determined by Pearson's correlation analysis

\begin{tabular}{|c|c|c|c|c|c|}
\hline \multirow{2}{*}{ Variable } & \multirow{2}{*}{ S.E. } & \multirow{2}{*}{ Odds ratio } & \multicolumn{2}{|c|}{$95 \% \mathrm{Cl}$} & \multirow{2}{*}{$\mathbf{P}$} \\
\hline & & & Lower & Upper & \\
\hline Age & 0.022 & 1.057 & 1.012 & 1.104 & $0.012^{* *}$ \\
\hline BMI & 0.068 & 1.075 & 0.941 & 1.229 & 0.288 \\
\hline TG & 0.003 & 1.008 & 1.002 & 1.015 & $0.014^{* *}$ \\
\hline HDL-C & 0.024 & 1.060 & 1.011 & 1.111 & $0.015^{* *}$ \\
\hline ET-2 & 0.098 & 1.349 & 1.114 & 1.634 & $0.002^{* *}$ \\
\hline Ox-LDL & 0.005 & 1.017 & 1.007 & 1.028 & $0.002^{* *}$ \\
\hline 8-isoPGF $2 a$ & 0.004 & 1.020 & 1.012 & 1.028 & $0.000^{\star * *}$ \\
\hline Nitrite & 0.001 & 1.004 & 1.002 & 1.006 & $0.000^{* \star *}$ \\
\hline
\end{tabular}

Note: S.E: Standard Error; Cl: Confidence Intervals; ${ }^{* \star} \mathrm{P}<0.01 ;{ }^{* \star *} \mathrm{P}<0.001$.

Table 3: Odds ratio of variables as determined by multivariate logistic regression analysis

\begin{tabular}{|l|c|c|c|}
\hline Variable & AUC (\%) & Cut-off value & Sensitivity (\%) \\
\hline ET-2 & 76.7 & 3.18 & 69.5 \\
\hline Ox-LDL & 79.1 & 61.5 & 92.6 \\
\hline 8-IsoPGF & 83.2 & 97.5 & 56.1 \\
\hline Nitrite & 75.4 & 822 & 63.2 \\
\hline
\end{tabular}

Table 4: Sensitivity and specificity of the variables as determined by receiver operating characteristic (ROC) curves
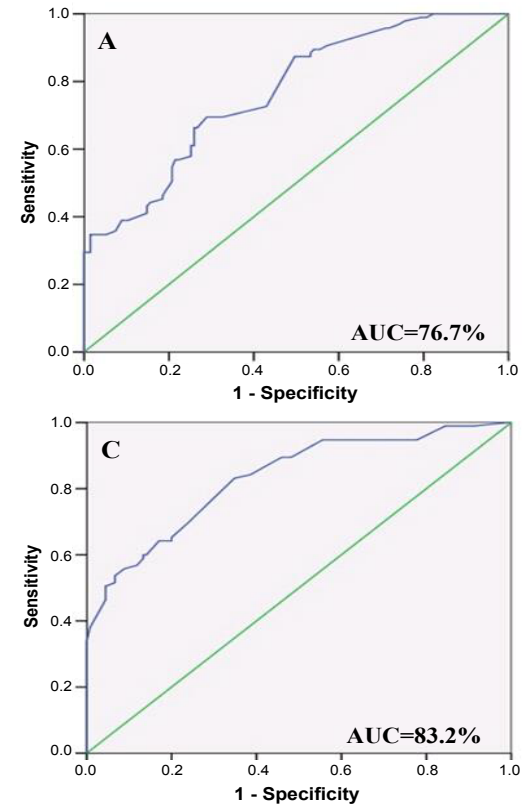
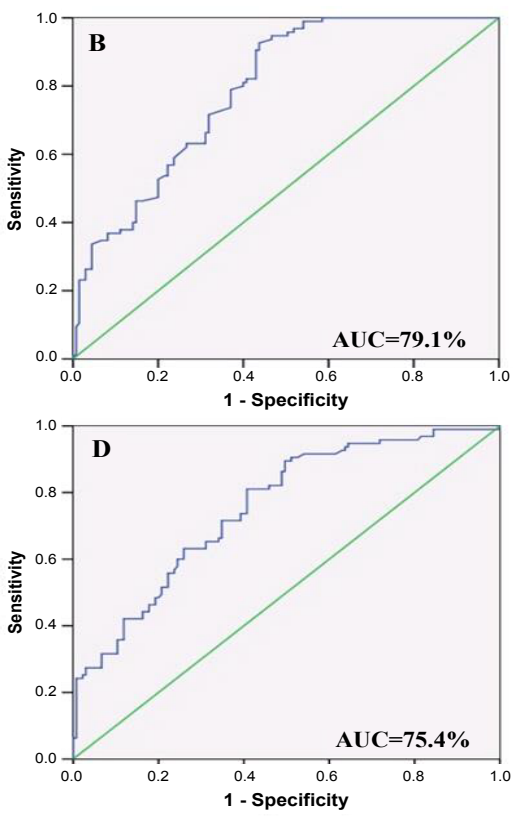

Figure 2: Receiver operating characteristic $(R O C)$ curves for ET-2 (A), Ox-LDL (B), 8-iso-PGF ${ }_{2 \alpha}(C)$ and Nitrite (D) for prediction of essential hypertension. 
sensitivity of $83.2 \%$ and specificity of $65.2 \%$ at a cutoff value of 97.5 $\mathrm{ng} / \mathrm{ml}$ was observed and for nitrite levels, $76.1 \%$ sensitivity and $66 \%$ specificity was achieved at a cut-off value of $822 \mu \mathrm{M}$ for prediction of essential hypertension in the study cohort (Table 4 and Figure 2).

\section{Discussion}

Essential hypertension is a major risk factor for Cardiovascular Diseases (CVD) and is a complex trait resulting from the interactions of multiple genetic and environmental determinants [23]. Endothelial dysfunction and oxidative stress seem to go parallel in hypertension, and may play a key role in the development and progression of CVD. Various in vitro and in vivo studies have demonstrated that oxidative stress influences several physiological processes including host defense, hormones biosynthesis, fertilization and cellular signaling and various pathologies, including hypertension, atherosclerosis, diabetes, and chronic kidney disease.

In the present study, the circulating levels of ET-2, Ox-LDL, 8 -isoPGF ${ }_{2 \alpha}$ and nitrite were found to be significantly higher in patients with $\mathrm{EH}$ as compared to their healthy counterparts. Further, correlation analysis demonstrated that ET-2 levels were positively correlated with ox-LDL, 8-isoPGF ${ }_{2 \alpha}$ and nitrite levels. Multiple regression analysis in our study further strengthens the importance of these molecules as observed by their high sensitivity and specificity. As far as ET-2 is concerned, there are very few reports suggesting the role of ET-2 in essential hypertension, as most of the studies have highlighted the role of ET-1 only. Our data for the first time indicates that ET-2 levels are able to distinguish hypertensives from healthy controls with remarkable sensitivity and specificity than controls. However, as far as ET-1 levels are concerned, we did not observe any significant difference between $\mathrm{EH}$ and control subjects (unpublished report). Though these values may not seem significant for clinical translation, our data stresses a need to revisit the role of ET-2 in hypertension. Our findings are in corroboration with a previous study where no difference in plasma ET-1 levels was observed between hypertensive patients and normotensive controls with normal renal function [24,25].

ET-2 KO mice show a distinct phenotype form than that of ET-1 and ET-3 [26] and a key role of ET-2 has been demonstrated in the development of pulmonary system [7]. These findings assume significance in view of the studies demonstrating clinical application of ET-receptor antagonists such as bosentan and ambrisentan in the treatment of pulmonary arterial hypertension. Endothelin-1 (ET-1) is a potent vasoconstrictor, shown to enhance oxidative stress, cell proliferation and reduce apoptosis in HUVECs via ET-RB NADPH oxidase [27]. Ruef et al. demonstrated that oxidative stress induced production and autocrine activity of ET-1 in VSMCs [28]. Sharma et al. in their study demonstrated a specific EDN2 polymorphism associated with essential hypertension [29]. However, few studies have demonstrated associations between rare ET-1 and ET-2 polymorphisms and lower diastolic blood pressures [30]. Poli et al reported that ET-2 exerts a strong positive inotropic effect on the human myocardium besides its effects on the vasculature [31]. Studies in human ET-2 (hET2) transgenic rats suggested that overexpression of ET-2 contributes to the development of glomerulosclerosis and myocardial fibrosis in diabetic rats $[32,33]$. These studies in KO mice suggest that ET-2 may have a role in CVD that is pathophysiologically distinct than ET-1, that may be accomplished at the level of gene expression or in their synthesis. In this context various clinical trials using endothelin antagonists have demonstrated potentially beneficial effects in patients with essential hypertension, pulmonary hypertension and heart failure [34]. Various studies have demonstrated that the ET-2 gene polymorphism (A985G) is significantly associated with increased incidence of atrial fibrillation [35-38]. Overall evidence from all these studies suggests that ET-2 may also modulate vascular tone like ET-1 and exert control on vascular tissue morphology and remodelling. Supporting the above statements, ET-2 has recently been shown to act as a chemokine and a modifier of leukocyte function, which may have significant implications in inflammatory diseases [39-41].

Corroborating our findings, ET-2 is also shown as a potent vasoconstrictor as ET-1, therefore, implying that ET-2, when released from the endothelial cells may also contribute to the physiological tone [42]. In this regard, two studies have reported that Big ET-2 circulates in human plasma at a higher level as compared to than Big ET-1 (biological inactive precursor of ET-1) though the levels of mature ET-2 are almost $1 / 5^{\text {th }}$ of mature ET-1 levels $[42,43]$.

We also observed significantly augmented ox-LDL levels in our study which by stimulating monocyte infiltration and smooth muscle cell migration and proliferation are shown to contribute to endothelial damage and dysfunction. Moreover, ox-LDL is shown to inhibit HDLassociated enzymes paraoxonase and PAF-acetyl hydrolase [44]. OxLDL acts through lectin-like receptor for ox-LDL (LOX-1) primarily in the endothelial cells. This receptor is shown to be highly expressed in the blood vessels of animals and humans with hypertension, diabetes mellitus and atherosclerosis [45]. Increased LDL oxidation levels have been observed in young men with borderline hypertension and decreased arterial elasticity, suggesting that oxidative modification of LDL particle reduces arterial dispensability in hypertension [46]. All the evidences outlined above support our data that ox-LDL levels are significantly augmented in subjects with essential hypertension.

Significantly augmented levels of 8 -isoPGF ${ }_{2 \alpha}$ in $\mathrm{EH}$ patients in our study suggested increased lipid peroxidation in these subjects [47-49].

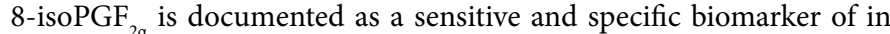
vivo oxidative stress. In our previous studies, we have also reported significantly increased levels of 8-isoPGF ${ }_{2 \alpha}$ in Takayasu's arteritis and endometriosis, two different conditions manifesting oxidative stress in their pathophysiology $[50,51] .8$-isoPGF ${ }_{2 a}$ is the most common isoprostane produced in vivo which is highly stable and acts as a potent renal vasoconstrictor with an $\mathrm{EC}_{50}$ in the low nanomolar range

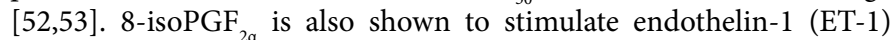
release from the aortic endothelial cells [54,55]. In this context, use of ET-antagonists in $\mathrm{HCH}$ pigs was shown to significantly attenuate the increase in isoprostanes and restore NO bioavailability, thereby reducing oxidative stress [18]. Although, the data regarding role of

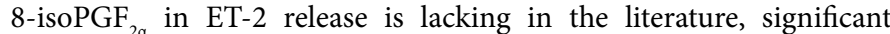

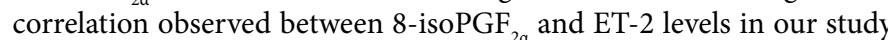
indicates that isoprostanes act as mediators in lipid peroxidationinduced vasoconstriction in hypertensives.

The data of the present study also reflects increased NO depletion as evident by significantly increased nitrite levels in subjects with $\mathrm{EH}$ as compared to the normal healthy controls. Further, our observations are also strengthened by finding a significant positive correlation among SBP, DBP, ET-2, Ox-LDL, 8-isoPGF ${ }_{2 \alpha}$ and nitrite levels in our study. A genome-wide analysis of the Framingham Heart Study $100 \mathrm{~K}$ project demonstrated an association between increased blood pressure and SNP of the human CAMKIV i.e. rs10491334 T/c, which suggests that this kinase may play a role in the regulation of vascular tone [56]. To assess the role of CAMKIV in hypertension, Santulli et al carried out a study in $\mathrm{CAMKIV}^{-1-}$ mice and demonstrated a typical hypertensive 
phenotype [57]. Similarly in a population study in hypertensive subjects, the same authors demonstrated that rs10491334 variant was associated with a reduction in the expression of CAMKIV levels and showed that CAMKIV regulates blood pressure via regulation of eNOS activity [57]. The GPCR kinases GRK2 and GRK5 are known to regulate $\beta$-adrenergic signaling. Recently, Lobmeyer et al. conducted a study in hypertensive populations who were being treated with either atenolol or an alternative therapy. Their data demonstrated that polymorphism in gene coding for GRK5 Leu41 protects these hypertensives against adverse cardiovascular outcomes, whereas a novel ADRBK1 promoter SNP demonstrated no association with BP response to anti-hypertensive drugs [58].

The data of the present study provides new insights regarding role of ET-2 in subjects with essential hypertension and also demonstrates its significant correlation with oxidative stress. It is evident that vasoconstriction increases at a stake of depleting vasoprotection because of prevailing oxidative milieu in subjects with essential hypertension. However, certain limitations in this study cannot be ruled out. Firstly, the number of the study subjects could be larger to draw a more logical conclusion. Secondly, any follow-up samples from EH subjects were not taken; therefore, effect of drugs on the variables under consideration could not be determined. Thirdly, the subjects enrolled in this study belong to North Indian population only, therefore, extrapolating the data to other ethnic groups is not recommended without further studies in this direction. Lastly, this is a cross-sectional study and any association found does not have any causal or diagnostic implication. Though, the biomarkers under consideration have emerged with significant sensitivity and specificity in the present study, however, their levels is not sufficient for translation in clinical practice. Hence, prospective studies are paramount to evaluate the effects of various drugs on these variables in larger number of patients with different durations of essential hypertension and other associated diseases.

\section{Acknowledgments}

Authors wish to thank Indian Council of medical research (ICMR), New Delhi for financial support. We also want to thank Shilpa Virdi, Gaurav Sharma and Lekhraj in collection and processing of samples.

\section{References}

1. Santulli, G (2013) Epidemiology of cardiovascular disease in the 21st century: updated numbers and updated facts. J Cardiovascular Diseases 1: 1-2.

2. Santulli G (2013) Coronary heart disease risk factors and mortality. JAMA 307 1137.

3. Go AS, Mozaffarian D, Roger VL, Benjamin EJ, Berry JD, et al. (2013) Heart disease and stroke statistics--2013 update: a report from the American Heart Association. Circulation 127: e6-e245.

4. Staessen JA, Wang J, Bianchi G, Birkenhäger WH (2003) Essentia hypertension. Lancet 361: 1629-1641.

5. Sharma P, Lu F, Rut A, Brown MJ (1998) Structure of human endothelin-2 gene and demonstration of common expression in human right atrial tissue. Biochem Biophys Res Commun 245: 709-712.

6. Sharma P, Hingorani A, Jia H, Hopper R, Brown MJ (1999) Quantitative association between a newly identified molecular variant in the endothelin-2 gene and human essential hypertension. J Hyperten 17: 1281-1287.

7. Ling L, Maguire JJ, Davenport AP (2013) Endothelin-2, the forgotten isoform emerging role in the cardiovascular system, ovarian development, immunology and cancer. Br J Pharmacol 168: 283-295.

8. Poli E, Casoli C, Spaggiari I, Starcich R, Bertaccini G (1991) Contractile effect of endothelin-2 on the isolated human saphenous vein. Arch Int Pharmacodyn Ther 313: 108-119.

9. Davenport AP, Maguire JJ (2006) Endothelin. Handb Exp Pharmacol : 295-329.
10. Nakhjavani M, Khalilzadeh O, Khajeali L, Esteghamati A, Morteza A, et al (2010) Serum oxidized-LDL is associated with diabetes duration independent of maintaining optimized levels of LDL-cholesterol. Lipids 45: 321-327.

11. Woodman RJ, Watts GF, Playford DA, Best JD, Chan DC (2005) Oxidized LDL and small LDL particle size are independently predictive of a selective defect in microcirculatory endothelial function in type 2 diabetes. Diabetes Obes Metab 7: 612-617.

12. Silverstein RL (2009) Inflammation, atherosclerosis, and arterial thrombosis: role of the scavenger receptor CD36. Cleve Clin J Med 76 Suppl 2: S27-S30.

13. Harrison DG, Gongora MC, Guzik TJ, Widder J (2007) Oxidative stress and hypertension. J Am Soc Hypertens 1: 30-44.

14. Praticò D, Lawson JA, Rokach J, FitzGerald GA (2001) The isoprostanes in biology and medicine. Trends Endocrinol Metab 12: 243-247.

15. Patrono C, FitzGerald GA (1997) Isoprostanes: potential markers of oxidant stress in atherothrombotic disease. Arterioscler Thromb Vasc Biol 17: 23092315.

16. Montuschi P, Barnes PJ, Roberts LJ 2nd (2004) Isoprostanes: markers and mediators of oxidative stress. FASEB J 18: 1791-1800.

17. Cracowski JL, Ormezzano O (2004) Isoprostanes, emerging biomarkers and potential mediators in cardiovascular diseases. Eur Heart J 25: 1675-1678.

18. Best PJM, Lerman LO, Romero JC, Holmes DR, Lerman A (1999) Chronic endothelial receptor antagonism preserves nitric oxide activity in experimental hypercholesterolemia. Arterioscler Thromb Vasc Biol 19: 2769-2775.

19. JNC-VI (1997) The sixth report of Joint National Committee on prevention, detection, evaluation and treatment of high blood pressure. Arch Intern Med 157: $2413-2446$

20. Friedewald WT, Levy RI, Fredrickson DS (1972) Estimation of the concentration of low-density lipoprotein cholesterol in plasma, without use of the preparative ultracentrifuge. Clin Chem 18: 499-502.

21. Green LC, Wagner DA, Glogowski J, Skipper PL, Wishnok JS, et al. (1982) Analysis of nitrate, nitrite, and [15N]nitrate in biological fluids. Anal Biochem 126: $131-138$

22. Dhawan V, Jain S (2005) Garlic supplementation prevents oxidative DNA damage in essential hypertension. Mol Cell Biochem 275: 85-94.

23. Kunes J, Zicha J (2009) The interaction of genetic and environmental factors in the etiology of hypertension. Physiol Res 58 Suppl 2: S33-S41.

24. Davenport AP, Ashby MJ, Easton P, Ella S, Bedford J, et al. (1990) A sensitive radioimmunoassay measuring endothelin-like immunoreactivity in human plasma: comparison of levels in patients with essential hypertension and normotensive control subjects. Clin Sci (Lond) 78: 261-264

25. Taddei S, Virdis A, Ghiadoni L, Sudano I, Notari M, et al. (1999) Vasoconstriction to endogenous endothelin- 1 is increased in the peripheral circulation of patients with essential hypertension. Circulation 100: 1680-1683.

26. Chang I, Bramall A, Baynash AG, Mcinnes RR, Stewart DJ, et al. (2009) Genetic study of ET-2 in mice. Eleventh International Conference on Endothelin, 15.

27. Dong F, Zhang X, Wold LE, Ren Q, Zhang Z, et al. (2005) Endothelin-1 enhances oxidative stress, cell proliferation and reduces apoptosis in human umbilical vein endothelial cells: role of ETB receptor, NADPH oxidase and caveolin-1. Br J Pharmacol 145: 323-333.

28. Ruef J, Moser M, Kübler W, Bode C (2001) Induction of endothelin-1 expression by oxidative stress in vascular smooth muscle cells. Cardiovasc Pathol 10: 311 -

29. Sharma P, Hingorani A, Jia H, Hopper R, Brown MJ (1999) Quantitative association between a newly identified molecular variant in the endothelin-2 gene and human essential hypertension. J Hypertens 17: 1281-1287.

30. Brown MJ, Sharma P, Stevens PA (2000) Association between diastolic blood pressure and variants of the endothelin-1 and endothelin-2 genes. J Cardiovasc Pharmacol 35: S41-S43.

31. Poli E, Barboso G, Casoli C, Starcich R, Bertaccini G (1991) Positive inotropic effect of endothelin-2 on human atrium preparations in vitro. Cardioscience 2 : 99-104.

32. Hocher B, Liefeldt L, Thöne-Reineke C, Orzechowski HD, Distler A, et al 
Citation: Dhawan V, Sharma I, Mahajan N, Sangwan SM, Jain S (2014) Implication of Endothelin-2 and Oxidative Stress Biomarkers in Essential Hypertension. J Hypertens 3: 170. doi:10.4172/2167-1095.1000170

(1996) Characterization of the renal phenotype of transgenic rats expressing the human endothelin-2 gene. Hypertension 28: 196-201.

33. Liefeldt L, Rylski B, Walcher F, Manhart J, Kron S, et al. (2010) Effects of transgenic endothelin-2 overexpression on diabetic cardiomyopathy in rats. Eur J Clin Invest 40: 203-210.

34. Agapitov AV, Haynes WG (2002) Role of endothelin in cardiovascular disease. J Renin Angiotensin Aldosterone Syst 3: 1-15

35. Channick RN, Simonneau G, Sitbon O, Robbins IM, Frost A, et al. (2001) Effects of the dual endothelin-receptor antagonist bosentan in patients with pulmonary hypertension: a randomised placebo-controlled study. Lancet 358 : 1119-1123.

36. Rubin LJ, Badesch DB, Barst RJ, Galie N, Black CM, et al. (2002) Bosentan therapy for pulmonary arterial hypertension. N Engl J Med 346: 896-903.

37. Barst RJ, Langleben D, Badesch D, Frost A, Lawrence EC, et al. (2006) Treatment of pulmonary arterial hypertension with the selective endothelin-A receptor antagonist sitaxsentan. J Am Coll Cardiol 47: 2049-2056.

38. Nagai T, Ogimoto A, Okayama H, Ohtsuka T, Shigematsu Y, et al. (2007) A985G polymorphism of the endothelin-2 gene and atrial fibrillation in patients with hypertrophic cardiomyopathy. Circ J 71: 1932-1936.

39. Wright CD, Cody WL, Dunbar JB Jr, Doherty AM, Hingorani GP, et al. (1994) Characterization of endothelins as chemoattractants for human neutrophils. Life Sci 55: 1633-1641.

40. Elferink JG, de Koster BM (1996) The effect of endothelin-2 (ET-2) on migration and changes in cytosolic free calcium of neutrophils. Naunyn Schmiedebergs Arch Pharmacol 353: 130-135.

41. Grimshaw MJ, Wilson JL, Balkwill FR (2002) Endothelin-2 is a macrophage chemoattractant: implications for macrophage distribution in tumors. Eur $\mathrm{J}$ Immunol 32: 2393-2400.

42. Maguire JJ, Davenport AP (1995) ETA receptor-mediated constrictor responses to endothelin peptides in human blood vessels in vitro. $\mathrm{Br} \mathrm{J}$ Pharmacol 115 191-197.

43. Matsumoto H, Suzuki N, Kitada C, Fujino M (1994) Endothelin family peptides in human plasma and urine: their molecular forms and concentrations. Peptides 15: $505-510$

44. Mertens A, Holvoet $P$ (2001) Oxidized LDL and HDL: antagonists in atherothrombosis. FASEB J 15: 2073-2084.

45. Mehta JL (2004) The role of LOX-, a novel lectin-like receptor for oxidized low density lipoprotein, in atherosclerosis. Can J Cardiol 20 Suppl B: 32B-36B.
46. Toikka JO, Niemi $P$, Ahotupa M, Niinikoski H, Rönnemaa T, et al. (2002) Decreased large artery distensibility in borderline hypertension is related to increased in vivo low-density lipoprotein oxidation. Scand J Clin Lab Invest 62: 301-306.

47. Morrow JD, Minton TA, Badr KF, Roberts LJ 2nd (1994) Evidence that the F2 isoprostane, 8-epi-prostaglandin F2 alpha, is formed in vivo. Biochim Biophys Acta 1210: $244-248$

48. Morrow JD, Roberts LJ 2nd (1996) The isoprostanes. Current knowledge and directions for future research. Biochem Pharmacol 51: 1-9.

49. Roberts LJ 2nd, Morrow JD (1997) The generation and actions of isoprostanes. Biochim Biophys Acta 1345: 121-135.

50. Mahajan N, Dhawan V, Malik S, Jain S (2010) Implication of oxidative stress and its correlation with activity of matrix metalloproteinases in patients with Takayasu's arteritis disease. Int J Cardiol 145: 286-288.

51. Sharma I, Dhaliwal LK, Saha SC, Sangwan S, Dhawan V (2010) Role of 8-isoprostaglandin F2alpha and 25-hydroxycholesterol in the pathophysiology of endometriosis. Fertil Steril 94: 63-70.

52. Morrow JD, Hill KE, Burk RF, Nammour TM, Badr KF, et al. (1990) A series of prostaglandin F2-like compounds are produced in vivo in humans by a noncyclooxygenase, free radical-catalyzed mechanism. Proc Natl Acad Sci U S A 87: 9383-9387.

53. Takahashi K, Nammour TM, Fukunaga M, Ebert J, Morrow JD, et al. (1992) Glomerular actions of a free radical-generated novel prostaglandin, 8-epiprostaglandin F2 alpha, in the rat. Evidence for interaction with thromboxane A2 receptors. J Clin Invest 90: 136-141.

54. Fukunaga M, Yura T, Badr KF (1995) Stimulatory effect of 8-Epi-PGF2 alpha, an F2-isoprostane, on endothelin-1 release. J Cardiovasc Pharmacol 26 Suppl 3: S51-52.

55. Lahaie I, Hardy P, Hou X, Hasséssian H, Asselin P, et al. (1998) A nove mechanism for vasoconstrictor action of 8-isoprostaglandin F2 alpha on retinal vessels. Am J Physiol 274: R1406-1416.

56. Levy D, Larson MG, Benjamin EJ, Newton-Cheh C, Wang TJ, et al. (2007) Framingham Heart Study $100 \mathrm{~K}$ Project: genome-wide associations for blood pressure and arterial stiffness. BMC Med Genet 8 Suppl 1: S3.

57. Santulli G, Cipolletta E, Sorriento D, Del Giudice C, Anastasio A, et al. (2012) CaMK4 Gene Deletion Induces Hypertension. J Am Heart Assoc 1: e001081.

58. Lobmeyer MT, Wang L, Zineh I, Turner ST, Gums JG, et al. (2011) Polymorphisms in genes coding for GRK2 and GRK5 and response differences in antihypertensive-treated patients. Pharmacogenet Genomics 21: 42-49. 